\title{
Differential effects of apolipoprotein E3 and E4 on markers of oxidative status in macrophages
}

\author{
Laia Jofre-Monseny ${ }^{1}$, Sonia de Pascual-Teresa ${ }^{2}$, Eva Plonka $^{1}$, Patricia Huebbe ${ }^{1}$, Christine Boesch-Saadatmandi ${ }^{1}$, \\ Anne-Marie Minihane ${ }^{3}$ and Gerald Rimbach ${ }^{1 *}$ \\ ${ }^{1}$ Institute of Human Nutrition and Food Science, Christian Albrechts University of Kiel, Hermann-Rodewald-Strasse 6, \\ 24098 Kiel, Germany \\ ${ }^{2}$ Department of Plant Food Sciences and Technology, CSIC, Instituto del Frio, Jose Anotonio Novais 10, Ciudad Universitaria, \\ Madrid, Spain \\ ${ }^{3}$ School of Chemistry, Food and Pharmacy, University of Reading, Reading RG6 6AP, UK
}

(Received 9 October 2006 - Revised 4 December 2006 - Accepted 5 December 2006)

\begin{abstract}
ApoE is secreted by macrophages at the lesion site of the atherosclerotic plaque, where it is thought to play a protective role against atherosclerosis independently of its effects on lipid metabolism. Of the three common isoforms for apoE, apoE4 is associated with higher risk of cardiovascular disease (CVD). In vitro studies have shown that recombinant apoE may act as an antioxidant in an isoform-dependent manner (E2 $>$ E3 $>$ E4). The oxidative status of the macrophages plays a key role in the process of atherosclerosis. In the present study the possible differential actions of apoE3 and apoE4 on several parameters of oxidative status were determined in stably transfected murine macrophages (RAW 264.7-apoE3 and apoE4). No differences between genotypes were observed after peroxide challenge in either protection against cytotoxicity or in cell membrane oxidation, and modest differences were observed in the non-enzymatic antioxidants (glutathione and $\alpha$-tocopherol) in apoE3 $v$. apoE4 macrophages. Importantly, cells secreting apoE4 showed increased membrane oxidation under basal conditions, and produced more NO and superoxide anion radicals than the apoE3 macrophages after stimulation. The present data suggest that apoE genotype influences the oxidative status of macrophages, and this could partly contribute to the higher CVD risk observed in apoE4 carriers.
\end{abstract}

apoE: Macrophage: Atherosclerosis: $\alpha$-Tocopherol: Lipid oxidation: Glutathione: Nitric oxide: Superoxide anion: Oxidative stress

ApoE plays an important role in cardiovascular homeostasis and is a recognised mediator of many metabolic processes underlying atherogenesis and thrombosis. This $34 \mathrm{kDa}$ protein, mainly produced by the liver, was first identified as a regulator of lipoprotein metabolism being involved in hepatic lipoprotein secretion, lipoprotein metabolism in the circulation and serving as a high-affinity ligand for cellular lipoprotein uptake. apoE is also secreted by many other tissues, and extra-hepatic apoE has been shown to protect against atherosclerosis independently of its effects on lipid metabolism (Yamada et al. 1992; Shimano et al. 1995; Fazio et al. 1997; Hasty et al. 1999). The protein is abundant in the atherosclerotic lesions, where resident macrophages are its principle source. The role of this locally produced apoE is not fully understood, but some identified effects include modulation of immunological functions in lymphocytes (Pepe \& Curtiss, 1986; Kelly et al. 1994; Mistry et al. 1995), inhibition of platelet aggregation (Riddell et al. 1997), regulation of smooth muscle cell migration and proliferation (Zeleny et al. 2002), and down-regulation of adhesion molecule expression in endothelial cells (Stannard et al. 2001). Apart from the effects on the surrounding cells, apoE is also thought to play an important role in macrophage metabolism acting as a modulator of cholesterol efflux (Bellosta et al. 1995; Shimano et al. 1995; Yoshida et al. 2001; Hara et al. 2003) and NO production (Colton et al. 2001, 2002). In addition, increasing evidence shows that apoE protects against oxidative reactions (Hayek et al. 1994; Pratico et al. 1998; Kitagawa et al. 2002), which may partly explain its anti-atherogenetic effects on vascular cell metabolism.

The apoE gene is polymorphic with two missense mutations resulting in three common allelic isoforms, apoE2, apoE3 and apoE4, which differ in the amino acids at positions 112 and 158 of the mature protein. apoE3 has Cys-112 and Arg-158, apoE2 has two cysteines and apoE4 has two arginines in these positions. apoE4 carriers (E3/E4, E4/E4), which represent $15-25 \%$ of Caucasian populations, have been shown to have a relative risk of CVD of 1.4-1.5 relative to the common E3/E3 genotype (Song et al. 2004). The increased CVD burden has traditionally been attributed to higher LDL cholesterol in E4 carriers. However, it is becoming increasingly apparent that the modest 3-8\% elevation in LDL cholesterol (Minihane et al. 2000) is unlikely to be the sole explanation for the difference in CVD incidence observed, and highlights the fact that the lipoproteins' apoE-mediated mechanisms are likely to

\footnotetext{
Abbreviations: AD, Alzheimer's disease; BSO, buthionine sulphoximine; GSH, reduced L-glutathione; LPS, lipopolysaccharide; PMA, phorbol myristate acetate. * Corresponding author: Prof. G. Rimbach, fax +49 0431 88802628, email rimbach@foodsci.uni-kiel.de
} 
contribute. Given that macrophages represent a significant source of apoE protein, which is a key regulator of the metabolism of the macrophages themselves and surrounding endothelial and smooth muscle cells and platelets, it is hypothesised that part of the disease differential is mediated by an impact of genotype on localised vascular wall metabolism.

A number of studies conducted in different models of Alzheimer's disease (AD) and atherosclerosis have reported a decreased antioxidant capacity of the apoE4 protein relative to apoE3 (Miyata \& Smith, 1996; Jolivalt et al. 2000; Tamaoka et al. 2000; Humphries et al. 2001; Dietrich et al. 2005; Talmud et al. 2005). Macrophage oxidative state, which is mainly determined by the balance between cellular oxygenases and macrophage-associated antioxidants (Aviram \& Fuhrman, 1998), is a key regulator of macrophage metabolism. The differential influence of the apoE isoforms on this balance remains largely unknown. The aim of the present study was to characterise murine macrophages which have been stably transfected with either the human apoE3 or apoE4 gene, in terms of indices of oxidative status.

\section{Materials and methods}

\section{Materials}

Specialised chemicals were obtained from Sigma-Aldrich (Taufkirchen, Germany): Griess-Reagent, lipopolysaccharide (LPS; Salmonella enteriditis), buthionine sulphoximine (BSO), phorbol myristate acetate (PMA), reduced L-glutathione $(\mathrm{GSH})$ and Sanger reagent. $\alpha$-Tocopherol used in cell culture was obtained from BASF (Ludwigshafen, Germany) and $\alpha$ - and $\delta$-tocopherol used as standards were obtained from Calbiochem (La Jolla, CA, USA). Neutral Red dye, nitroblue tetrazolium and dimethyl sulphoxide were purchased from Carl Roth (Karlsruhe, Germany). C11-BODIPY ${ }^{581 / 591}$ was obtained from Molecular Probes, Invitrogen (Karlsruhe, Germany). Specialised HPLC solvents were purchased from Mallinckrodt Baker BV (Deventer, The Netherlands). RAW 264.7 cells lines stably transfected with either human apoE3 or apoE4 were kindly given by Dr B. Pitas (Gladstone Institute, UCSF, USA). This model was chosen since the murine RAW 264.7 cells have been previously used to study differential effects of human apoE isoforms on monocyte function as these cells do not produce appreciable amounts of apoE (Miyata \& Smith, 1996; Smith et al. 1996). Cell culture medium, fetal bovine serum, penicillin/streptomycin and G-418 were from PAA Laboratories (Coelbe, Germany).

\section{Cell culture}

RAW 264-7-apoE3 and -apoE4 cells were cultured in Dulbecco's modified Eagle medium supplemented with $10 \%$ fetal bovine serum, $4 \mathrm{~mm}$-L-glutamine, $100 \mu \mathrm{g} / \mathrm{ml}$ penicillin and $100 \mu \mathrm{g} / \mathrm{ml}$ streptomycin, and $100 \mu \mathrm{g} / \mathrm{ml} \mathrm{G}-418$. Cells were grown in a humidified incubator at $37^{\circ} \mathrm{C}$ and $5 \% \mathrm{CO}_{2}$.

\section{Cell lines assessment for apoE (genotype and protein levels)}

For genotype cells, DNA was extracted from cell pellets using the QIAamp DNA Blood Mini Kit (Qiagen Ltd, Crawley, $\mathrm{UK})$. The apoE region, which includes the two apoE polymorphic sites, was amplified by PCR using the following primers: 5'-ACA GAA TTC GCC CCG GCC TGG TAC AC-3' (forward) and 5'-TAA GCT TGG CAC GGC TGT CCA AGG A-3' (reverse). The amplified sequence was digested using the HhaI restriction enzyme, and the resultant fragments were separated and characterised by gel electrophoresis as described by Hixson \& Vernier (1990).

ApoE protein concentrations were measured in cell supernatants to ensure that secreted levels were similar among the two clones. Protein was concentrated by using Vivaspin 20 columns (Sartorius, Epsom, UK). apoE concentration was determined by an automated turbimetric immunoassay kit (Apolipoprotein E-HA Wako, Alpha Laboratories Ltd, Eastleigh, UK) on the ILAB 600 automatic analyser (Instrumentation Laboratories UK Ltd, Warrington, UK). Total cell protein was measured with the BCA kit (Pierce Biotechnology, Rockford, IL, USA).

\section{Assessment of peroxide-induced cell death}

RAW 264.7-apoE3 and -apoE4 cells were seeded at $1.5 \times 10^{5}$ cells/well in twenty-four-well plates and grown for $48 \mathrm{~h}$. Cells were then challenged with either tert-butyl hydroperoxide or $\mathrm{H}_{2} \mathrm{O}_{2}$ at increasing concentrations $(100 \mu \mathrm{M}$ to $2 \mathrm{mM})$ in serumfree media for $3 \mathrm{~h}$. Cell viability was measured by the Neutral Red assay (Borenfreund \& Puerner, 1985) with slight modifications. Cells were incubated with the dye for $2 \mathrm{~h}$ and washed twice with PBS before extraction of the Neutral Red into solution. Cell viability (Neutral Red uptake) was determined by reading absorbance at $540 \mathrm{~nm}$ (Labsystems iEMS Reader; Labsystems, Helsinki, Finland). Results were expressed as absorbance observed as a percentage of control cultures.

\section{Oxidation of C11-BODIPY $Y^{581 / 591}$}

The lipid peroxidation reporter molecule C11-BODIPY ${ }^{581 / 591}$ (Pap et al. 1999) was used to examine the oxidation of membranes in macrophages. The C11-BODIPY ${ }^{581 / 591}$ dye is a lipophilic substance which incorporates into membranes and is useful to assess membrane oxidation since its oxidised and its reduced forms fluorescence at different wavelengths. C11-BODIPY ${ }^{581 / 591}$ oxidation was assessed under basal conditions and after oxidation. Macrophages were incubated with $\mathrm{C} 11-\mathrm{BODIPY} \mathrm{Y}^{581 / 591}(10 \mu \mathrm{M})$ for $30 \mathrm{~min}$ at $37^{\circ} \mathrm{C}$ in growth medium. After labelling, cells were washed with PBS, and oxidation was induced by addition of cumene hydroperoxide $(80 \mu \mathrm{M})$ and hemin $(80 \mathrm{nM})$ in PBS and incubated for $1 \mathrm{~h}$ at $37^{\circ} \mathrm{C}$. Control cells were incubated with PBS only. A multi-well spectrofluorometer (Optima; BMG Labtech, Offenburg, Germany) was used to measure green $(485 / 520 \mathrm{~nm})$ and red $(544 / 590 \mathrm{~nm})$ fluorescence intensity. Oxidation of C11-BODIPY ${ }^{581 / 591}$ was calculated as the ratio between green fluorescence (oxidised) and total fluorescence (oxidised plus reduced), to normalise for dye incorporation into cellular membranes.

\section{$\alpha$-Tocopherol and buthionine sulphoximine cytotoxicity test}

In order to ensure that the $\alpha$-tocopherol and BSO concentrations used for further experiments were not cytotoxic, cells were subcultured in twenty-four-well plates $\left(1.5 \times 10^{5}\right.$ 
cells/well) $24 \mathrm{~h}$ before experimental treatment. Cells were incubated with test substances at increasing concentrations (up to $100 \mu \mathrm{M}$ for $\alpha$-tocopherol and $200 \mu \mathrm{M}$ for buthionine sulphoximine) for $24 \mathrm{~h}$ and the Neutral Red assay was carried out.

\section{Glutathione levels}

To determine whether apoE genotype had an influence on GSH levels under basal conditions, after treatment with $\alpha$-tocopherol and upon GSH depletion, cells were incubated for $24 \mathrm{~h}$ with vehicle $(0 \cdot 1 \%$ ethanol), $\alpha$-tocopherol $(50 \mu \mathrm{M}$ in $0.1 \%$ ethanol) or BSO $(50 \mu \mathrm{M}$ in PBS), an inhibitor of $\gamma$-glutamylcysteine synthetase, the rate-limiting enzyme for GSH de novo synthesis. After treatments, cells were washed twice and scraped on ice with cold PBS and then centrifuged. Cell pellets were frozen in liquid nitrogen and stored at $-80^{\circ} \mathrm{C}$. Pellets were resuspended with $100 \mu \mathrm{l}$ PBS and sonicated, an aliquot was used to determine protein concentration by the BCA kit, and $80 \mu \mathrm{l}$ of sample was prepared for GSH determination (Hernandez-Montes et al. 2006).

Briefly, after protein precipitation with TCA (5\%) containing $0.2 \mathrm{~mm}$-desferal, GSH was derivatised by addition of iodoacetic acid to yield 5-carboxymethyl glutathione, and this was followed by complexation with dinitrofluorobenzene (Sanger Reagent). The resulting complex was analysed by HPLC analysis with UV detection by a modification of the method of Yoshida (1996).

\section{Vitamin E concentration}

To investigate whether the apoE genotype had an influence on the intracellular accumulation of $\alpha$-tocopherol after its supplementation, macrophages were subcultured in six-well plates and grown for $24 \mathrm{~h}$. Treatments with $\alpha$-tocopherol and collection of samples were similar to that described by Gao et al. (2002). In summary, medium was enriched with $\alpha$-tocopherol $(5$ and $50 \mu \mathrm{M})$ for $6 \mathrm{~h}$. Adherent cells were washed with PBS and were overlaid with $420 \mu$ l lysis buffer ( $1 \%$ Triton X-100 in pH 7.5, 20 mM-HEPES buffer with $0 \cdot 1 \mathrm{~mm}$-EDTA) and scraped. One aliquot was collected for protein determination and 2,6-di-tert-butyl-4-methylphenol was added to the other aliquot samples, which were stored for tocopherol analysis. $\delta$-Tocopherol was used as internal standard. Cell samples were mixed with ethanol-1\% ascorbate $(1: 1 \cdot 5)$ and with hexane $(1: 2 \cdot 5)$ and were vortexed for $30 \mathrm{~s}$. After phase separation, the upper layer was removed and dried under $\mathrm{N}_{2}$. Samples were resuspended in methanol. For the HPLC analysis, the mobile phase was methanol-water (98:2) isocratically delivered at a flow rate of $1.2 \mathrm{ml} / \mathrm{min}$. The tocopherol content was analysed using a Jasco HPLC system on a Waters Spherisorb ODS-2 $3 \mu \mathrm{m}$ column $(100 \times 4.6 \mathrm{~mm})$ with the detector set to an excitation wavelength of $290 \mathrm{~nm}$ and emission wavelength of $325 \mathrm{~nm}$.

\section{NO production}

NO production was assessed by determining the amount of its stable metabolite, nitrite $\left(\mathrm{NO}_{2}^{-}\right)$, in culture supernatants using the Griess reaction. Cells were pretreated for $24 \mathrm{~h}$ with $\alpha$-tocopherol $(50 \mu \mathrm{M})$ or ethanol $(0 \cdot 1 \%)$ and then stimulated for $4 \mathrm{~h}$ with LPS $(1 \mu \mathrm{g} / \mathrm{ml})$. Removal of LPS was carried out by washing twice with PBS, and fresh culture medium was added. After $20 \mathrm{~h}$, supernatants were collected for nitrite measurement by the Griess reaction. Samples were processed as described elsewhere (Rimbach et al. 2003) and nitrite concentration was determined by reading its absorbance at $540 \mathrm{~nm}$ (Labsystems iEMS Reader) using a standard curve for sodium nitrite.

\section{Determination of intracellular superoxide anion production}

A colorimetric assay was used to compare the amount of superoxide anion $\left(\mathrm{O}_{2}^{-}\right)$production by RAW 264.7-apoE3 and -apoE4 after stimulation with PMA. Superoxide anion was determined by the quantitative nitroblue tetrazolium assay (Choi et al. 2006) with the only modification being that cells were grown in twenty-four-well plates and were stimulated for $1 \mathrm{~h}$ with increasing concentrations of PMA $(0.25-1 \mu \mathrm{g} / \mathrm{ml})$ in serum-free medium containing $0.05 \%$ nitroblue tetrazolium (total volume of $500 \mu \mathrm{l} /$ well). After dissolving the deposited nitroblue tetrazolium inside the cells, the solution was transferred into ninety-six-well plates and read at $620 \mathrm{~nm}$ (Labsystems iEMS Reader).

\section{Statistical analysis}

Statistical calculations were conducted with SPSS version 13.0 (SPSS Inc., Chicago, IL, USA). $t$ Tests (for independent samples) were performed to compare the outcomes between apoE3 and apoE4 cells. In the absence of normal distributed data, the Mann-Whitney $U$ test was used. Results are expressed as means and their standard errors, and significance was accepted at $P<0 \cdot 05$.

\section{Results}

\section{Cell lines assessment for apoE}

Genotyping confirmed that the RAW 264.7 cell lines contained the gene coding for either human apoE3 or apoE4. apoE protein levels secreted in the medium in $24 \mathrm{~h}$ were found to be similar in both clones $(1.38$ (SEM0.38) $\mu \mathrm{g} / \mathrm{mg}$ cell protein for apoE3, and $1 \cdot 36$ (SEM0.38) for apoE4) and within the human physiological range (Wang-Iverson et al. 1985).

\section{$\alpha$-Tocopherol and buthionine sulphoximine cytotoxicity test}

Incubation of cells with $\alpha$-tocopherol up to $100 \mu \mathrm{M}$, and BSO up to $200 \mu \mathrm{M}$ for $24 \mathrm{~h}$ did not produce any changes in cell viability in RAW 264.7-apoE3 and -apoE4 as determined by the Neutral Red test.

\section{Assessment of peroxide-induced cell death}

At a concentration of $750 \mu \mathrm{M}-\mathrm{H}_{2} \mathrm{O}_{2}$, a modest loss of cell viability was evident (16\% for apoE3 and $20 \%$ for apoE4). At a concentration of $1 \mathrm{~mm}$-tert-butyl hydroperoxide a similar amount of cell death occurred (6\% for apoE3 and $20 \%$ for apoE4) (Fig. 1(A, B)). At higher exposure of both substances, viability decreased in a dose-dependent manner. However, no significant differences between genotypes could be observed in the cytotoxicity dose-response curves. 

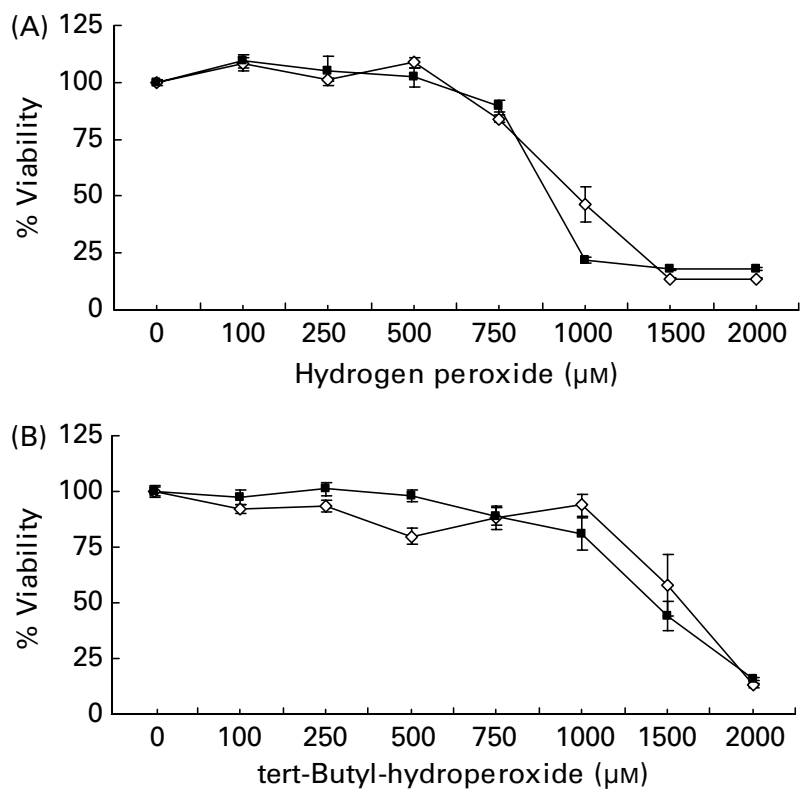

Fig. 1. Viability of apoE3 $(\diamond)$ and apoE4 $(\mathbf{\square})$ stably transfected macrophages in response to peroxide challenge. RAW 264.7-apoE3 and -apoE4 cells were treated with either $\mathrm{H}_{2} \mathrm{O}_{2}$ (A) or tert-butyl hydroperoxide (B) at increasing concentrations $(100 \mu \mathrm{M}$ to $2 \mathrm{~mm}$ ) in serum-free medium for $3 \mathrm{~h}$. Cell viability was measured using the Neutral Red assay. Values, expressed as \% viability relative to controls, are means with their standard errors depicted by vertical bars (two independent experiments performed in triplicate).

\section{Oxidation of C11-BODIPY $Y^{581 / 591}$}

In cells where oxidative stress was not externally induced (baseline conditions), RAW 264-7-apoE4 showed an approximately $40 \%$ increase $(P<0.001)$ in the oxidation ratio as compared to RAW 264.7-apoE3 (Fig. 2). One hour after induction with cumene hydroperoxide/hemin, the ratio increased considerably in both cases, but no differences could be observed between the two isoforms.

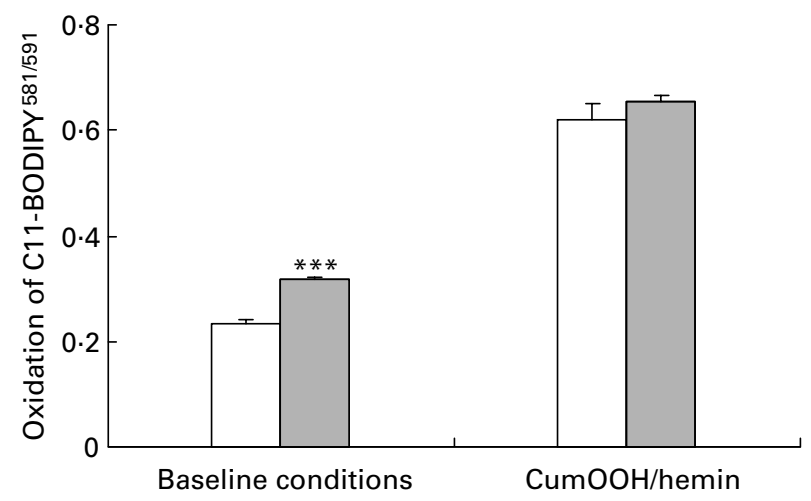

Fig. 2. Comparison of C11-BODIPY ${ }^{581 / 591}$ dye oxidation in apoE3 ( $\square$ ) and apoE4 ( $\square$ ) macrophages. Cells were labelled with C11-BODIPY581/591 and oxidation was induced by addition of cumene hydroperoxide $(\mathrm{CumOOH}$; $80 \mu \mathrm{M})$ and hemin $(80 \mathrm{~nm})$ for $1 \mathrm{~h}$ at $37^{\circ} \mathrm{C}$. Baseline cells were incubated with PBS only. Fluorescence intensity was measured at green $(485 / 520 \mathrm{~nm})$ and red $(544 / 590 \mathrm{~nm})$ wavelengths. Oxidation of C11-BODIPY ${ }^{581 / 591}$ is expressed as the ratio between green fluorescence (oxidised) and total fluorescence (oxidised plus reduced). Values are means with their standard errors depicted by vertical bars (three or more independent experiments performed in quadruplicate). Mean values were significantly different from those of the apoE3 group: ${ }^{* \star *} P<0 \cdot 001$.

\section{Glutathione levels}

Intracellular glutathione levels were analysed in untreated cells (controls), and in cells incubated for $24 \mathrm{~h}$ with either $\alpha$-tocopherol $(50 \mu \mathrm{M})$ or BSO $(50 \mu \mathrm{M})$. Although there was a trend for cells expressing apoE3 to exhibit higher levels of GSH, no significant differences could be observed between genotypes (Fig. 3). The amount of glutathione in untreated RAW 264.7-apoE3 and -apoE4 was 8.9 (SEM 2.1) and 8.5 (SEM 3.5) $\mathrm{nmol} / \mathrm{mg}$ protein, respectively. A modest $16 \%$ $(P=0.38)$ and 6\% $(P=0.75)$ increase in GSH levels were evident in apoE3 and apoE4 cells following $\alpha$-tocopherol supplementation. BSO almost completely abolished GSH synthesis, so that only 8.7 and $5.1 \%$ of the GSH levels found in controls could be detected in cells expressing apoE3 and apoE4, respectively.

\section{Vitamin E accumulation}

Incubation with $\alpha$-tocopherol for $6 \mathrm{~h}$ at $5 \mu \mathrm{M}$ resulted in an accumulation of vitamin $\mathrm{E}$ in macrophages of 1.8 (SEM 0.5) and 1.3 (SEM 0.4) nmol $\alpha$-tocopherol/mg protein in apoE3 and apoE4 cells, respectively (Fig. 4). Enrichment of medium with $50 \mu \mathrm{M}-\alpha$-tocopherol for the same time period resulted in an approximately 10-fold increase of vitamin $\mathrm{E}$ detected in cell pellets (16.2 (SEM 3.7) and 13.8 (SEM 3.9) nmol $\alpha$-tocopherol/ $\mathrm{mg}$ protein for apoE3 and apoE4, respectively). Although in both tested concentrations there was a trend for apoE3 macrophages to accumulate more $\alpha$-tocopherol, differences were not statistically significant.

\section{NO production}

Twenty hours after stimulation of macrophages with LPS $(1 \mu \mathrm{g} /$ $\mathrm{ml}$ ) for $4 \mathrm{~h}$, macrophages showed a substantial increase in NO production (Fig. 5). The nitrite concentration in the medium from RAW 264.7-apoE4 was $6 \%$ higher than in RAW 264.7apoE3 $(P=0 \cdot 028)$. Pre-incubation with $\alpha$-tocopherol $(50 \mu \mathrm{M})$ for $24 \mathrm{~h}$ reduced NO production in a genotype-dependent manner. RAW 264.7-apoE3 were more sensitive to vitamin E,

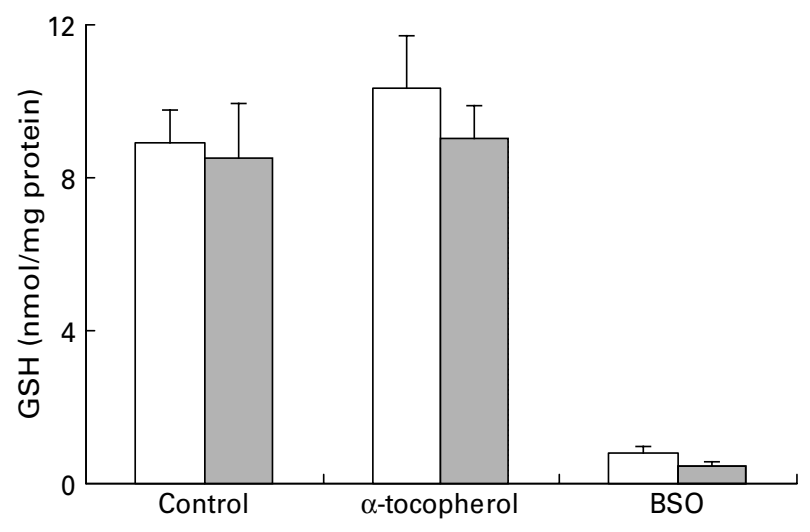

Fig. 3. Determination of reduced L-glutathione (GSH) levels in apoE3 ( $\square$ ) and apoE4 ( $\square$ ) macrophages. Cells were treated with $0.1 \%$ ethanol (control), $\alpha$-tocopherol $(50 \mu \mathrm{M})$ or buthionine sulphoximine (BSO; $50 \mu \mathrm{M}$ ) for $24 \mathrm{~h}$. Intracellular GSH levels were assessed as outlined in the Materials and Methods. Values are means with their standard errors depicted by vertical bars (three independent experiments performed in duplicate). 


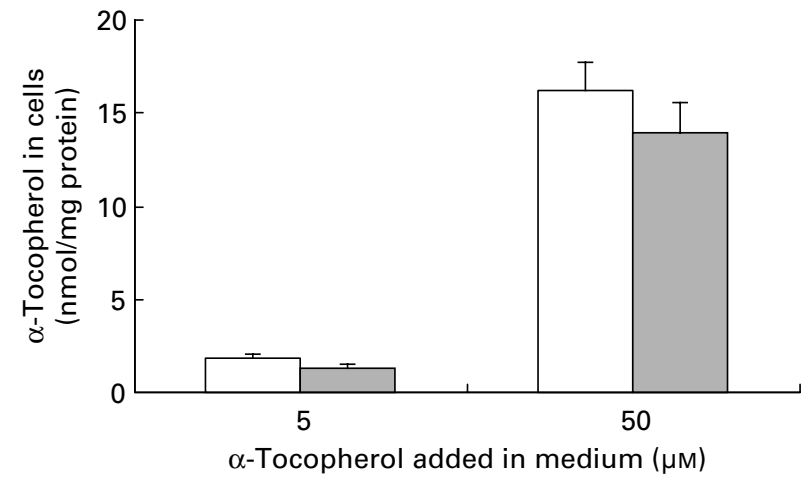

Fig. 4. Comparison of $\alpha$-tocpherol accumulation in apoE3 ( $\square$ ) and apoE4 ( $\square$ ) macrophages. RAW 264.7-apoE3 and -apoE4 were incubated with $\alpha$ tocopherol $(5$ and $50 \mu \mathrm{M})$ for $6 \mathrm{~h}$ and then intracellular concentration of vitamin E was analysed by HPLC as indicated in the Materials and Methods. Values are means with their standard errors depicted by vertical bars (three independent experiments performed in duplicate).

with a $20 \%$ reduction in nitrite, compared to a $7 \%$ decrease evident in RAW 264.7-apoE4.

\section{Superoxide production}

After $1 \mathrm{~h}$ stimulation with PMA at increasing concentrations, the superoxide anion radical production increased in a dosedependent way in both genotypes (Fig. 6). The amount of superoxide produced by the apoE4 macrophages was consistently higher in all the PMA doses tested. At $0.25 \mu \mathrm{g} / \mathrm{ml}$ PMA, cells expressing apoE4 produced $30 \%$ more $\mathrm{O}_{2}^{--}$than the apoE3 macrophages $(P=0.005)$. At 0.5 and $1 \mu \mathrm{g} / \mathrm{ml}$ PMA, RAW264.7-apoE4 showed an increase of almost $60 \%$ in $\mathrm{O}_{2}^{\cdot-}$ production $(P=0.002$ and $P=0.001)$.

\section{Discussion}

In addition to its well-described role in lipoprotein metabolism, apoE is becoming increasingly recognised for its role in numerous metabolic pathways within the vascular intima. Although the impact of apoE may be mediated by a cell-signalling

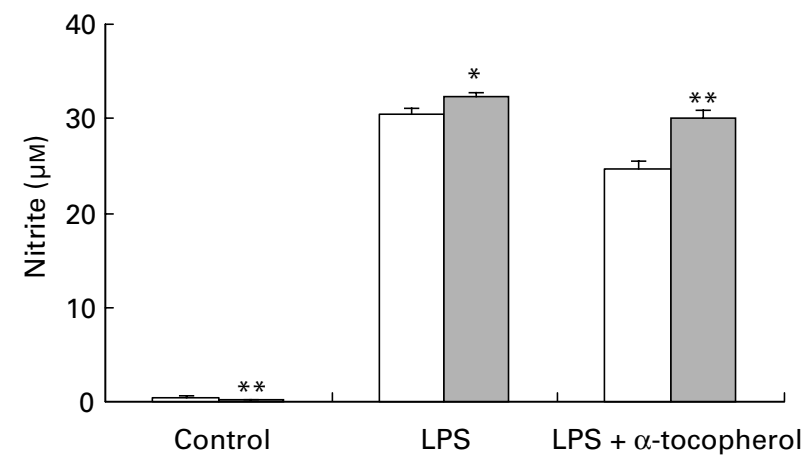

Fig. 5. Evaluation of NO production in apoE3 $(\square)$ and apoE4 ( $\square$ ) macrophages. NO was assessed by determining the amount of its stable metabolite, nitrite $\left(\mathrm{NO}_{2}^{-}\right)$in culture supernatants using the Griess reaction. Cells were pretreated for $24 \mathrm{~h}$ with $\alpha$-tocopherol or ethanol $(0.1 \%)$ and then stimulated for $4 \mathrm{~h}$ with lipopolysaccharide (LPS) $(1 \mu \mathrm{g} / \mathrm{ml})$. Supernatants were collected $20 \mathrm{~h}$ later for nitrite analysis. Values are means with their standard errors depicted by vertical bars (three independent experiments performed in duplicate). Mean values were significantly different from those of the apoE3 group: ${ }^{\star} P<0.05 ;{ }^{\star \star} P<0.01$.

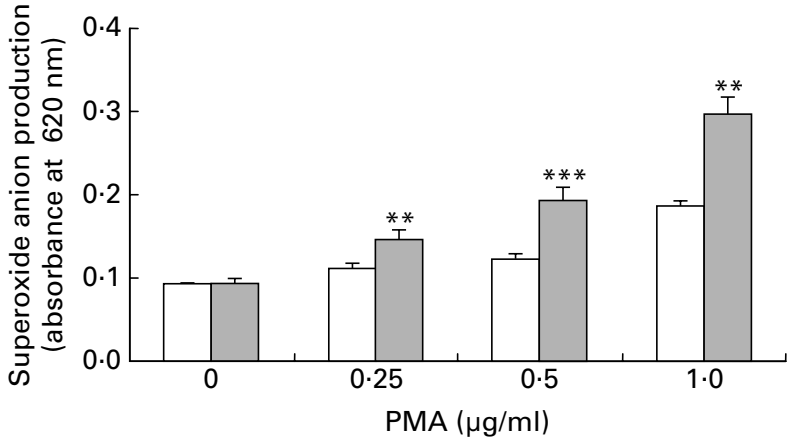

Fig. 6. Comparison of superoxide anion radical production between RAW 264.7-apoE3 ( $\square$ ) and -apoE4 ( $\square$ ). Attached cells were stimulated with increasing concentrations of phorbol myristate acetate (PMA; $0.25-1 \mu \mathrm{g} / \mathrm{ml}$ ) in the presence of $0.05 \%$ nitroblue tetrazolium for $1 \mathrm{~h}$. Superoxide anion production was determined by the quantitative nitroblue tetrazolium assay of Choi et al. (2006 Values are means with their standard errors depicted by vertical bars (three independent experiments performed in triplicate). Mean values were significantly different from those of the apoE3 group: ${ }^{\star \star} P<0.01$; ${ }^{\star \star \star} P<0.001$.

process stimulated by interaction of apoE with cell surface apolipoprotein receptors, it is likely to be in part attributable to its antioxidant capacity within the relatively antioxidantdepleted environment of the vascular wall. In vitro studies have consistently reported differences in the antioxidant capacity of the different isoforms (Miyata \& Smith, 1996). In macrophages, oxidative stress triggers a cycle of events which exacerbates lesion formation. The impact of genotype independently of apoE concentration on the oxidative status of macrophages is unknown and was the topic of the current investigation.

Since cellular apoE location is mainly associated with surface-connected compartments of the plasma cell membrane (Bellosta et al. 1995; Duan et al. 1997), the possible differential effects of apoE3 and apoE4 in protecting against membrane damage induced by $\mathrm{H}_{2} \mathrm{O}_{2}$ and tert-butyl hydroperoxide were investigated. The Neutral Red assay was chosen since it is a viability test sensitive to cell membrane injury. A shift in the cytotoxicity dose-response curve between apoE isoforms was not evident in our macrophage cell model. This differs from the results of Miyata \& Smith (1996), who showed protection of apoE3 $>$ E4 against $\mathrm{H}_{2} \mathrm{O}_{2}$-mediated cytotoxicity in rat neuronal $\mathrm{B} 12$ cell line after incubation with conditioned media containing either apoE3 or apoE4 (Miyata \& Smith, 1996). In addition to possible cell-specific differences, an explanation to these contradictory results could be that our cell model exposed the cells to endogenously produced apoE, which is arguably a more physiological approach, rather than adding exogenous apoE to the cell culture medium.

To further determine whether the different apoE isoforms have an effect on the rate of membrane oxidation, cells were loaded with the C11-BODIPY ${ }^{581 / 591}$ dye, which can be incorporated readily into lipid bilayers by its fatty acyl chain and monitors the oxidation of unsaturated fatty acids in the membranes (Naguib, 1998; Pap et al. 1999; Drummen et al. 2004). Spontaneous oxidation of the dye (baseline levels) was significantly higher in RAW 264.7-apoE4 than in RAW 264.7-apoE3. Following stress induced by a free radical generation system (cumene hydroperoxide/hemin), lipid oxidation considerably increased in a genotype-independent manner. 
This is likely due to an inability of either isoform to protect against oxidation in a highly oxidising saturated environment. Similar results have been observed in the frontal cortex of AD brains, as measured by thiobarbituric acid reactive substances (Ramassamy et al. 2000), in which under basal conditions, there was a genotype effect of apoE in lipid peroxidation (E4 $>$ E3), but after complete oxidation of the samples, no difference could be observed between genotypes. In any case both CVD and $\mathrm{AD}$ pathology are a result of chronic modest insults and it is likely that the genotype differences in lipid oxidation observed could make a meaningful contribution to the development of these diseases. Previously, the limited data in man was suggestive that genotype differences in oxidative status may be attributable to the lower circulating apoE protein levels in E4 carriers. As both E3 and E4 cells lines used in the current study secrete equivalent apoE protein levels, the data indicates that differences in the antioxidant capacity of the E3 and E4 isoforms may also make a significant contribution.

ApoE4 carriers have been suggested as a population that could potentially benefit from vitamin E supplementation (Peroutka \& Dreon, 2000). $\alpha$-Tocopherol is the most biologically active form of vitamin $\mathrm{E}$ and is known to be effectively accumulated by RAW 264.7 cells (Gao et al. 2002; McCormick \& Parker, 2004). Furthermore, in the current study its impact on macrophage oxidative status was determined. Accumulation studies indicated a trend towards higher concentrations of $\alpha$-tocopherol in apoE3 compared to apoE4 transfected cells. In vivo LDL and HDL represent the major vitamin $\mathrm{E}$ carriers in the bloodstream, with apoE mediating the cellular uptake of HDL to scavenger receptor class B type 1 (Mardones et al. 2002). apoE4 has preferential affinity to VLDL rather than HDL, which could lead to a decreased uptake of vitamin $\mathrm{E}$ in the macrophages (or other tissues), and increased concentration in plasma. In fact, higher plasma vitamin E levels in apoE4 carriers have previously been reported (Lodge et al. 2004). However, any trends observed in the cell culture system may not be directly attributed to this potential mechanism as vitamin $\mathrm{E}$ was delivered in ethanol and not in lipoproteins. Furthermore, due to the nature of the experiment, it cannot be elucidated whether these small differences are due to lower uptake or to higher metabolism of vitamin $\mathrm{E}$ in apoE4 macrophages.

Glutathione is an important intracellular antioxidant found mainly in the cytosol, and it plays a pivotal role in maintaining the macrophage redox balance. In particular, GSH participates in the detoxification of peroxides, and in addition, it can determine the rate of LDL oxidation in these cells (Gotoh et al. 1993). It was shown that mouse peritoneal macrophages from apoE-deficient mice had reduced GSH levels and increased lipid peroxides (Rosenblat et al. 2002). In addition, $\alpha$-tocopherol has been shown to increase GSH in mouse peritoneal macrophages (Rosenblat et al. 2002). For these reasons, intracellular GSH concentrations were measured in RAW 264.7-apoE3 and -apoE4 under basal conditions and after incubation of cells with $\alpha$-tocopherol at $50 \mu \mathrm{M}$, a concentration which was not cytotoxic and which falls within the reachable concentrations in plasma (Jialal et al. 1995). In the present study, only a small decrease in GSH could be observed in E4 in respect to E3 under basal conditions. These results are in accordance with the findings of Ramassamy et al. (2000) and Fernandes et al.
(1999), who found no differences in the GSH concentration according to apoE genotype either in the frontal cortex or in the plasma of AD patients. Incubation of cells with $\alpha$-tocopherol $(50 \mu \mathrm{M})$ for $24 \mathrm{~h}$ induced a small increase in the GSH concentrations, which may be in part attributable to the small differences found in vitamin $\mathrm{E}$ accumulation. Furthermore, cells from both genotypes responded similarly to GSH depletion by incubation with BSO $(50 \mu \mathrm{M})$, which inhibits the de novo synthesis of GSH.

Activated macrophages generate NO and superoxide anion $\left(\mathrm{O}_{2}^{-}\right)$which react to produce peroxynitrite, a strong oxidant, which is centrally involved in the pathogenesis of atherosclerosis. The rate of this reaction is faster than the rate of superoxide anion radical scavenging by superoxide dismutase (Beckman \& Koppenol, 1996); therefore, NO can influence the fate of superoxide. NO is produced by nitric oxide synthase, with the induction of nitric oxide synthase occurring by activation of NF- $\mathrm{B}$, but also by other mechanisms, including the activation of NADPH oxidases (Zhou et al. 1999). It has been shown that apoE regulates the response to LPS in vivo (Ali et al. 2005), and modulates NO production in macrophages, in a genotype-dependent way (E4 $>$ E3; Colton et al. 2004). Additionally $\alpha$-tocopherol has been shown to inhibit NF- $\kappa \mathrm{B}$ activation by LPS (Asehnoune et al. 2004). The present results confirm that RAW 264-7-apoE4 produce more NO than RAW 264.7-apoE3 following LPS stimulation. In addition, we show that apoE3 macrophages respond better to a pretreatment with $\alpha$-tocopherol, since NO production was reduced by $20 \%$ in apoE3 in comparison to $7 \%$ in apoE4. The molecular mechanism by which apoE modulates LPS effects, and its possible synergism with vitamin E, need to be further investigated.

On the other hand, to assess the production of $\mathrm{O}_{2}^{-}$, cells were stimulated with PMA, an activator of the NADPH oxidase. It has been reported that NADPH oxidase-dependent superoxide produced by infiltrated monocytes is associated with atherosclerosis, as well as with thickness of carotid intima-media, even before appearance of clinical atherosclerotic disease (Bokoch $\&$ Knaus, 2003). The present results show a significant increase in superoxide anion radical production in apoE4 in comparison to apoE3 macrophages, in the three doses of PMA tested. The present data suggest that differential modulating effects of apoE3 and apoE4 on the NADPH oxidase system could partly contribute to the higher risk of CVD observed in apoE4 carriers. The hypothesis that apoE may influence the NADPH oxidase activity is supported by the fact that in apoE-deficient mice, mouse peritoneal macrophages secreted twofold more superoxide anions than the mouse peritoneal macrophages from the wild type (Rosenblat \& Aviram, 2002).

Peroxidation of cellular lipids and the formation of oxysterols have been considered responsible for the increased NADPH oxidase activity in apoE-deficient mice (Rosenblat \& Aviram, 2002). Increased content of oxysterols in E4 is plausible since differential oxidation of membrane lipids was observed in the present study $(\mathrm{E} 4>\mathrm{E} 3)$, and this could partly contribute to the increased NADPH oxidase activity in apoE4 cells.

The mechanism by which apoE acts as an antioxidant, and why it is isoform-dependent, is not entirely understood. There are several putative mechanisms which include metal binding activity (Miyata \& Smith, 1996), the presence of a thiol group 
(Cys 112) in apoE3, and recent work indicating that the most plausible mechanism relies on the radical scavenging activity of positively charged amino acids found in the receptor binding domain of the apolipoprotein (Pham et al. 2005). Due to the exchange of a Cys by an Arg at position 112 in apoE4, a domain interaction arises which leads to a less stable protein, with folding intermediates which are more rapidly degraded and which influence the affinity of apoE for different lipoproteins (Hatters et al. 2006). This could also have an impact on the antioxidant capacity of the protein (Pham et al. 2005).

The current study is suggestive that an impact of apoE genotype on monocyte oxidative status may contribute to the higher CVD and AD risk observed in man. However, it needs to be taken into account that cell culture models have limitations, and it is not possible to mimic the course of a chronic disease in vitro. Further clarification of the impact of apoE genotype on oxidative status using in vivo animal models and human trials is needed.

\section{Conclusions}

Taken together, current data indicate that apoE genotype affects several parameters which determine the oxidant/antioxidant status of macrophages. Differences (apoE4 $>$ apoE3) in membrane oxidation under basal conditions and in $\mathrm{NO}$ and superoxide anion radical production upon macrophage stimulation with LPS and PMA, respectively, were observed. Moreover, pretreatment with $\alpha$-tocopherol was able to decrease LPS-induced NO production in E3 $>$ E4. On the other hand, small differences were observed in the concentrations of intracellular GSH and $\alpha$-tocopherol (apoE3 $>$ apoE4). Taken together the data are suggestive of increased oxidative stress in macrophages which may be an important contributing factor to the higher CVD risk in apoE4 $v$. apoE3 carriers. Finally, the findings of the current trial are suggestive that antioxidant interventions, such as increased vitamin $\mathrm{C}$, vitamin $\mathrm{E}$ or polyphenols, could serve to reduce the $40-50 \%$ increased risk of CVD evident in E4 carriers.

\section{Acknowledgements}

We thank Dr B. Pitas (Gladstone Institute, USA) who kindly provided us with the RAW 264.7 cells expressing apoE3 and apoE4. The work was partially funded by the Spanish/ German Programme Acciones Integradas Hispano-Alemanas (ref. HA2004-0091) and by a Ramon y Cajal grant to Sonia de Pascual Teresa.

\section{References}

Ali K, Middleton M, Pure E \& Rader DJ (2005) Apolipoprotein E suppresses the type I inflammatory response in vivo. Circ Res $\mathbf{9 7}$, 922-927.

Asehnoune K, Strassheim D, Mitra S, Kim JY \& Abraham E (2004) Involvement of reactive oxygen species in Toll-like receptor 4-dependent activation of NF-kappa B. J Immunol 172, 2522-2529.

Aviram M \& Fuhrman B (1998) LDL oxidation by arterial wall macrophages depends on the oxidative status in the lipoprotein and in the cells: role of prooxidants vs. antioxidants. Mol Cell Biochem 188, 149-159.
Beckman JS \& Koppenol WH (1996) Nitric oxide, superoxide, and peroxynitrite: the good, the bad, and ugly. Am J Physiol 271, C1424-C1437.

Bellosta S, Mahley RW, Sanan DA, Murata J, Newland DL, Taylor JM \& Pitas RE (1995) Macrophage-specific expression of human apolipoprotein $\mathrm{E}$ reduces atherosclerosis in hypercholesterolemic apolipoprotein E-null mice. J Clin Invest 96, 2170-2179.

Bokoch GM \& Knaus UG (2003) NADPH oxidases: not just for leukocytes anymore! Trends Biochem Sci 28, 502-508.

Borenfreund E \& Puerner JA (1985) Toxicity determined in vitro by morphological alterations and neutral red absorption. Toxicol Lett 24, 119-124.

Choi HS, Kim JW, Cha YN \& Kim C (2006) A quantitative nitroblue tetrazodium assay for determining intracellular superoxide anion production in phagocytic cells. J Immunoassay Immunochem 27, $31-44$.

Colton CA, Brown CM, Cook D, Needham LK, Xu Q, Czapiga M, Saunders AM, Schmechel DE, Rasheed K \& Vitek MP (2002) APOE and the regulation of microglial nitric oxide production: a link between genetic risk and oxidative stress. Neurobiol Aging 23, 777-785.

Colton CA, Czapiga M, Snell-Callanan J, Chernyshev ON \& Vitek MP (2001) Apolipoprotein E acts to increase nitric oxide production in macrophages by stimulating arginine transport. Biochim Biophys Acta 1535, 134-144.

Colton CA, Needham LK, Brown C, Cook D, Rasheed K, Burke JR, Strittmatter WJ, Schmechel DE \& Vitek MP (2004) APOE genotype-specific differences in human and mouse macrophage nitric oxide production. J Neuroimmunol 147, 62-67.

Dietrich M, Hua Y, Block G, Olano E, Packer L, Morrow JD, Hudes M, Abdukeyum G, Rimbach G \& Minihane AM (2005) Associations between apolipoprotein E genotype and circulating F2-isoprostane levels in humans. Lipids 40, 329-334.

Drummen GP, Makkinje M, Verkleij AJ, Op den Kamp JA \& Post JA (2004) Attenuation of lipid peroxidation by antioxidants in rat-1 fibroblasts: comparison of the lipid peroxidation reporter molecules cis-parinaric acid and C11-BODIPY(581/591) in a biological setting. Biochim Biophys Acta 1636, 136-150.

Duan H, Lin CY \& Mazzone T (1997) Degradation of macrophage ApoE in a nonlysosomal compartment. Regulation by sterols. J Biol Chem 272, 31156-31162.

Fazio S, Babaev VR, Murray AB, Hasty AH, Carter KJ, Gleaves LA, Atkinson JB \& Linton MF (1997) Increased atherosclerosis in mice reconstituted with apolipoprotein E null macrophages. Proc Natl Acad Sci U S A 94, 4647-4652.

Fernandes MA, Proenca MT, Nogueira AJ, Grazina MM, Oliveira LM, Fernandes AI, Santiago B, Santana I \& Oliveira CR (1999) Influence of apolipoprotein $\mathrm{E}$ genotype on blood redox status of Alzheimer's disease patients. Int J Mol Med 4, 179-186.

Gao R, Stone WL, Huang T, Papas AM \& Qui M (2002) The uptake of tocopherols by RAW $264 \cdot 7$ macrophages. Nutr J 1, 2.

Gotoh N, Graham A, Nikl E \& Darley-Usmar VM (1993) Inhibition of glutathione synthesis increases the toxicity of oxidized low-density lipoprotein to human monocytes and macrophages. Biochem J 296, Part 1, 151-154.

Hara M, Matsushima T, Satoh H, Iso-o N, Noto H, Togo M, Kimura S, Hashimoto Y \& Tsukamoto K (2003) Isoform-dependent cholesterol efflux from macrophages by apolipoprotein $\mathrm{E}$ is modulated by cell surface proteoglycans. Arterioscler Thromb Vasc Biol 23, 269-274.

Hasty AH, Linton MF, Brandt SJ, Babaev VR, Gleaves LA \& Fazio S (1999) Retroviral gene therapy in ApoE-deficient mice: ApoE expression in the artery wall reduces early foam cell lesion formation. Circulation 99, 2571-2576.

Hatters DM, Peters-Libeu CA \& Weisgraber KH (2006) Apolipoprotein E structure: insights into function. Trends Biochem Sci 31, 445-454. 
Hayek T, Oiknine J, Brook JG \& Aviram M (1994) Increased plasma and lipoprotein lipid peroxidation in apo E-deficient mice. Biochem Biophys Res Commun 201, 1567-1574.

Hernandez-Montes E, Pollard SE, Vauzour D, Jofre-Montseny L, Rota C, Rimbach G, Weinberg PD \& Spencer JP (2006) Activation of glutathione peroxidase via Nrf1 mediates genistein's protection against oxidative endothelial cell injury. Biochem Biophys Res Commun 346, 851-859.

Hixson JE \& Vernier DT (1990) Restriction isotyping of human apolipoprotein $\mathrm{E}$ by gene amplification and cleavage with HhaI. $J$ Lipid Res 31, 545-548.

Humphries SE, Talmud PJ, Hawe E, Bolla M, Day IN \& Miller GJ (2001) Apolipoprotein E4 and coronary heart disease in middleaged men who smoke: a prospective study. Lancet 358, 115-119.

Jialal I, Fuller CJ \& Huet BA (1995) The effect of alpha-tocopherol supplementation on LDL oxidation. A dose-response study. Arterioscler Thromb Vasc Biol 15, 190-198.

Jolivalt C, Leininger-Muller B, Bertrand P, Herber R, Christen Y \& Siest G (2000) Differential oxidation of apolipoprotein E isoforms and interaction with phospholipids. Free Radic Biol Med 28, 129-140.

Kelly ME, Clay MA, Mistry MJ, Hsieh-Li HM \& Harmony JA (1994) Apolipoprotein $\mathrm{E}$ inhibition of proliferation of mitogen-activated $\mathrm{T}$ lymphocytes: production of interleukin 2 with reduced biological activity. Cell Immunol 159, 124-139.

Kitagawa K, Matsumoto M, Kuwabara K, Takasawa K, Tanaka S, Sasaki T, Matsushita K, Ohtsuki T, Yanagihara T \& Hori M (2002) Protective effect of apolipoprotein E against ischemic neuronal injury is mediated through antioxidant action. $J$ Neurosci Res 68, 226-232.

Lodge JK, Hall WL, Jeanes YM \& Proteggente AR (2004) Physiological factors influencing vitamin E biokinetics. Ann N Y Acad Sci 1031, 60-73.

Mardones P, Strobel P, Miranda S, Leighton F, Quinones V, Amigo L, Rozowski J, Krieger M \& Rigotti A (2002) Alpha-tocopherol metabolism is abnormal in scavenger receptor class B type I (SR-BI)-deficient mice. $J$ Nutr 132, 443-449.

McCormick CC \& Parker RS (2004) The cytotoxicity of vitamin E is both vitamer- and cell-specific and involves a selectable trait. J Nutr 134, 3335-3342.

Minihane AM, Khan S, Leigh-Firbank EC, Talmud P, Wright JW, Murphy MC, Griffin BA \& Williams CM (2000) ApoE polymorphism and fish oil supplementation in subjects with an atherogenic lipoprotein phenotype. Arterioscler Thromb Vasc Biol 20, 1990-1997.

Mistry MJ, Clay MA, Kelly ME, Steiner MA \& Harmony JA (1995) Apolipoprotein $\mathrm{E}$ restricts interleukin-dependent $\mathrm{T}$ lymphocyte proliferation at the G1A/G1B boundary. Cell Immunol 160, 14-23.

Miyata M \& Smith JD (1996) Apolipoprotein E allele-specific antioxidant activity and effects on cytotoxicity by oxidative insults and beta-amyloid peptides. Nat Genet 14, 55-61.

Naguib YM (1998) A fluorometric method for measurement of peroxyl radical scavenging activities of lipophilic antioxidants. Anal Biochem 265, 290-298.

Pap EH, Drummen GP, Winter VJ, Kooij TW, Rijken P, Wirtz KW, Op den Kamp JA, Hage WJ \& Post JA (1999) Ratio-fluorescence microscopy of lipid oxidation in living cells using C11BODIPY(581/591). FEBS Lett 453, 278-282.

Pepe MG \& Curtiss LK (1986) Apolipoprotein E is a biologically active constituent of the normal immunoregulatory lipoprotein, LDL-In. J Immunol 136, 3716-3723.

Peroutka SJ \& Dreon DM (2000) The value of genotyping for apolipoprotein $\mathrm{E}$ alleles in relation to vitamin E supplementation. Eur J Pharmacol 410, 161-163.

Pham T, Kodvawala A \& Hui DY (2005) The receptor binding domain of apolipoprotein $\mathrm{E}$ is responsible for its antioxidant activity. Biochemistry 44, 7577-7582.
Pratico D, Lee VM-Y, Trojanowski JQ, Rokach J \& Fitzgerald GA (1998) Increased F2-isoprostanes in Alzheimer's disease: evidence for enhanced lipid peroxidation in vivo. FASEB J 12, 1777-1783.

Ramassamy C, Averill D, Beffert U, Theroux L, Lussier-Cacan S, Cohn JS, Christen Y, Schoofs A, Davignon J \& Poirier J (2000) Oxidative insults are associated with apolipoprotein E genotype in Alzheimer's disease brain. Neurobiol Dis 7, 23-37.

Riddell DR, Graham A \& Owen JS (1997) Apolipoprotein E inhibits platelet aggregation through the L-arginine:nitric oxide pathway. Implications for vascular disease. J Biol Chem 272, 89-95.

Rimbach G, De Pascual-Teresa S, Ewins BA, Matsugo S, Uchida Y, Minihane AM, Turner R, VafeiAdou K \& Weinberg PD (2003) Antioxidant and free radical scavenging activity of isoflavone metabolites. Xenobiotica 33, 913-925.

Rosenblat M \& Aviram M (2002) Oxysterol-induced activation of macrophage NADPH-oxidase enhances cell-mediated oxidation of LDL in the atherosclerotic apolipoprotein E deficient mouse: inhibitory role for vitamin E. Atherosclerosis 160, 69-80.

Rosenblat M, Coleman R \& Aviram M (2002) Increased macrophage glutathione content reduces cell-mediated oxidation of LDL and atherosclerosis in apolipoprotein E-deficient mice. Atherosclerosis 163, 17-28.

Shimano H, Ohsuga J, Shimada M, Namba Y, Gotoda T, Harada K, Katsuki M, Yazaki Y \& Yamada N (1995) Inhibition of dietinduced atheroma formation in transgenic mice expressing apolipoprotein $\mathrm{E}$ in the arterial wall. $J$ Clin Invest 95, 469-476.

Smith JD, Miyata M, Ginsberg M, Grigaux C, Shmookler E \& Plump AS (1996) Cyclic AMP induces apolipoprotein E binding activity and promotes cholesterol efflux from a macrophage cell line to apolipoprotein acceptors. J Biol Chem 271, 30647-30655.

Song Y, Stampfer MJ \& Liu S (2004) Meta-analysis: apolipoprotein E genotypes and risk for coronary heart disease. Ann Intern Med 141, 137-147.

Stannard AK, Riddell DR, Sacre SM, Tagalakis AD, Langer C, von Eckardstein A, Cullen P, Athanasopoulos T, Dickson G \& Owen JS (2001) Cell-derived apolipoprotein E (ApoE) particles inhibit vascular cell adhesion molecule-1 (VCAM-1) expression in human endothelial cells. J Biol Chem 276, 46011-46016.

Talmud PJ, Stephens JW, Hawe E, Demissie S, Cupples LA, Hurel SJ, Humphries SE \& Ordovas JM (2005) The significant increase in cardiovascular disease risk in APOE\&4 carriers is evident only in men who smoke: potential relationship between reduced antioxidant status and ApoE4. Ann Hum Genet 69, 613-622.

Tamaoka A, Miyatake F, Matsuno S, et al. (2000) Apolipoprotein E allele-dependent antioxidant activity in brains with Alzheimer's disease. Neurology 54, 2319-2321.

Wang-Iverson P, Gibson JC \& Brown WV (1985) Plasma apolipoprotein secretion by human monocyte-derived macrophages. Biochim Biophys Acta 834, 256-262.

Yamada N, Inoue I, Kawamura M, et al. (1992) Apolipoprotein E prevents the progression of atherosclerosis in Watanabe heritable hyperlipidemic rabbits. J Clin Invest 89, 706-711.

Yoshida H, Hasty AH, Major AS, Ishiguro H, Su YR, Gleaves LA, Babaev VR, Linton MF \& Fazio S (2001) Isoform-specific effects of apolipoprotein $\mathrm{E}$ on atherogenesis: gene transduction studies in mice. Circulation 104, 2820-2825.

Yoshida T (1996) Determination of reduced and oxidized glutathione in erythrocytes by high-performance liquid chromatography with ultraviolet absorbance detection. J Chromatogr B Biomed Appl 678, $157-164$

Zeleny M, Swertfeger DK, Weisgraber KH \& Hui DY (2002) Distinct apolipoprotein $\mathrm{E}$ isoform preference for inhibition of smooth muscle cell migration and proliferation. Biochemistry 41, 11820-11823.

Zhou J, Struthers AD \& Lyles GA (1999) Differential effects of some cell signalling inhibitors upon nitric oxide synthase expression and nuclear factor-kappaB activation induced by lipopolysaccharide in rat aortic smooth muscle cells. Pharmacol Res 39, 363-373. 